\title{
A Negociação Intersubjetiva de Significados em Jogos de Interpretação de Papéis ${ }^{1}$
}

\author{
Danilo Silva Guimarães² \\ Lívia Mathias Simão \\ Universidade de São Paulo
}

\begin{abstract}
RESUMO - Este artigo focaliza o processo de negociação intersubjetiva de significados por meio da análise microgenética de sessões de Jogos de Interpretação de Papéis (Role-Playing Games). Partiu-se da suposição de que a análise de interações eu - outro durante o jogo poderia evidenciar aspectos relevantes para a compreensão das relações entre intersubjetividade e alteridade em contextos interpessoais. Os resultados da análise microgenética dos diálogos entre os jogadores evidenciaram a participação de processos psicológicos relevantes para o desenvolvimento humano, em que momentos de tensão e inquietação, característicos das relações de alteridade, alternavam-se com momentos de convergência e compartilhamento sobre os temas da conversa e sobre as posições relativas dos interlocutores.
\end{abstract}

Palavras-chave: construtivismo semiótico-cultural; intersubjetividade; alteridade; desenvolvimento humano; Role-Playing Games.

\section{Intersubjective Negotiation of Meanings in Role-Playing Games}

\begin{abstract}
This article focuses on the intersubjective process of meaning negotiation, through microgenetic analysis of Role-Playing Game sessions. We departed from the supposition that the analysis of I-other interactions, during that game, could put in evidence relevant aspects for the comprehension of the relation between intersubjectivity and otherness in interpersonal contexts. The results of the microgenetic analysis of the dialogues among the players showed the participation of important psychological processes in human development. In those processes, moments of tension and disquiet - typical of otherness relationships - were alternated with moments of convergence and sharing about the topics of the dialogue, as well as about the relational positions of the interlocutors.
\end{abstract}

Keywords: semiotic-cultural constructivism; intersubjectivity; otherness; human development; Role-Playing Games.

Uma das principais vias de transformação no desenvolvimento humano ocorre por meio da busca do sujeito pelo compartilhamento de experiências com o outro, isto é, da busca pela intersubjetividade. Neste artigo serão discutidos aspectos do processo de negociação intersubjetiva de significados, ilustrando-os com trechos de análise microgenética (Valsiner, 1989) de sessões de Jogos de Interpretação de Papéis, mais conhecidos como Role-Playing Games (RPG).

Conforme propõe e discute Valsiner (1989), a análise microgenética visa apreender o processo de emergência de novidade nos fenômenos psicológicos que estão sempre imbricados na 'nebulosidade' das interações concretas das pessoas com seu contexto. No caso desta pesquisa, a análise microgenética está voltada para os momentos de rupturas e transições no compartilhamento de significados entre jogadores de RPG.

Consideramos a análise dos diálogos entre os jogadores interessante para ilustrar o processo de negociação intersubjetiva de significados por duas razões, que de certa forma são, ao mesmo tempo, complementares e antagônicas. Por

1 A presente pesquisa foi desenvolvida com Bolsa de Iniciação Científica da FAPESP concedida ao primeiro autor, sob orientação da segunda autora.

2 Endereço: Rua José Alves Cunha Lima, 159, ap. 2031, Butantã. São Paulo, SP. CEP 05360-050.E-mail: danilosg@usp.br. um lado, o RPG não se destaca como acontecimento esporádico, mas é parte inerente da vida cotidiana, rotineira, dos jogadores. Por outro lado, por ser um espaço lúdico, fantasioso, o RPG tem um âmbito de realidade vivenciada, contextual, que o destaca de outros contextos rotineiros da vida cotidiana.

Malaby (2007) oferece uma concepção valiosa para a compreensão da perspectiva teórico-metodológica que vimos desenvolvendo e apresentamos, em parte, neste artigo. Para ele, "um jogo é um domínio semi-aberto e socialmente legitimado de contingência limitada que gera resultados interpretáveis" (p. 96). Malaby destaca ainda que os jogos são acontecimentos relativamente independentes da vida cotidiana, na medida em que, em seu cerne, variam muito pouco com relação ao que existe material, social e culturalmente. Mais importante é que, segundo esse autor, ao mesmo tempo em que os jogos produzem prazer, eles também podem produzir muitos outros estados emocionais, vinculados à carga de significado atribuída ao jogo em cada contexto particular.

Parte dos estados emocionais referidos por Malaby (2007) diz respeito, em nossa pesquisa, às relações eu - outro que têm lugar no RPG. As relações intersubjetivas são vivenciadas pelos participantes do jogo, tanto no nível real (como pessoas conhecidas entre si que decidiram formar um grupo de RPG), quanto no nível imaginário (por meio da interpretação de personagens assumidos no jogo). 
A partir da perspectiva acima sintetizada, analisamos diálogos durante sessões de RPG buscando focalizar aspectos da relação eu-outro que evidenciassem a percepção mútua de um e do outro como diferentes, quer como jogadores, quer como personagens imaginados, remetendo-nos a questões atinentes aos temas da intersubjetividade, ruptura intersubjetiva e alteridade.

\section{Imaginação, Subjetividade e Intersubjetividade}

O domínio da intersubjetividade é marcado pela negociação e renegociação de proposições entre os interlocutores, que funcionam como balizas ${ }^{3}$ organizadoras de suas experiências pessoais. Considerando-se o desenvolvimento humano como processo semi-aberto, as pessoas precisam estabelecer, em suas interações, uma base temporária ou um domínio de união compartilhada, sobre os quais alguma negociação seja possível. Esse domínio compartilhado é chamado intersubjetividade (Valsiner, 1998).

Crossley (1996) destaca o fato de que alguns autores - tais como Schutz - consideram que as relações intersubjetivas que se estabelecem com os contemporâneos, predecessores e sucessores, podem ocorrer também no nível imaginário, quando o sujeito interage 'como se' os interlocutores estivessem presentes.

Nessa mesma direção, Hermans (1996) salienta que os outros que permeiam nossa vida em diálogos imaginários privados são resultado de uma derivação de nossas relações com os outros da realidade 'objetiva'. Hermans, Kempen e van Loon (1992) propõem o mundo interno como um mundo social imaginado, em que o eu flutua em diferentes posições no self de uma mesma pessoa, interagindo como diferentes personagens, criando perspectivas alternativas do mundo e de si-mesmo. O self seria, então, um espaço mental, onde os outros imaginados seriam percebidos como exteriores a nós mesmos (Hermans 1996; Hermans \& cols., 1992) ${ }^{4}$.

Rommetveit (1979) aponta, por sua vez, que a intersubjetividade só é possível através da descentração do ego, quando o sujeito tenta 'interpretar o papel' da outra pessoa, ou seja, quando assume o ponto de vista do interlocutor e também a crença de que o interlocutor está empenhado em entender e em se fazer entender. Assim, ambos - sujeito e interlocutor - transcendem seus próprios mundos individuais, o que coloca a intersubjetividade "como um meta processo de reflexividade que leva constantemente à criação, manutenção e mudança do sentido pessoal de 'fundo' da atividade dialógica (a figura)" (Valsiner, 1998, p. 33).

Considerando que o raciocínio humano opera com base na experiência vivida, as perspectivas propostas tanto por Hermans e cols. (1992) como por Valsiner (1998) apontam para a intersubjetividade como um processo que ocorre não só entre as pessoas, mas também entre diferentes níveis de funcionamento semiótico do sujeito individual, no diálogo polifônico entre seus vários selves.

3 Optamos por traduzir o termo constraint, do inglês, por baliza, em português, conforme Valsiner (2006).

4 A noção de self na psicologia tem uma trajetória de tal amplitude que sua explicitação e discussão fogem ao âmbito deste artigo. Cabe explicitar que adotamos a noção de self de Hermans (1996, 2002).
Quanto à relação entre subjetividade e intersubjetividade, Crossley (1996) propõe que (a) a subjetividade não é matéria privada, do mundo interno, mas é pública e intersubjetiva; (b) a subjetividade consiste em uma abertura pré-reflexiva e engajamento com a alteridade, ao invés de experiência objetivante da alteridade; (c) a ação humana, particularmente a fala, assume aí uma forma socialmente instituída, essencial para seu significado; e (d) muito da experiência e ação humanas surge de situações dialógicas ou sistemas irredutíveis aos sujeitos humanos individuais. Segundo esse autor, a subjetividade, conceitualizada segundo esses quatro pontos, será necessariamente intersubjetiva, isto é, remetida a um intermundo irredutível de significados compartilhados.

Crossley (1996) também distingue duas fases da intersubjetividade, uma denominada de intersubjetividade radical e outra, intersubjetividade egológica. A intersubjetividade radical envolve um relacionamento mútuo, uma relação imediata de harmonização do self com o outro de tal modo que ele não experimenta a si mesmo como tal, havendo uma abertura incondicional para o outro e prevalecendo o endereçamento do eu à alteridade. A intersubjetividade egológica é entendida como intencionalidade empática em que o eu experimenta o outro reflexivamente, a partir de uma transposição imaginária do seu self para o lugar do outro, por meio de analogia.

\section{Sobre os Role-Playing Games}

A primeira versão dos RPGs modernos foi lançada em 1974, por Dave Arneson e Gary Gygax, adaptando os populares jogos de estratégia de guerra para jogos com personagens fantásticos. Ao invés dos jogadores atuarem no manejo de exércitos, um dos jogadores passou a fazer o papel de personagem de uma aventura, enquanto o outro organizava o cenário e interpretava personagens secundários. Dessa maneira, iniciouse a interpretação de personagens individuais e 'encarnados', em contraposição ao manejo de grupos de miniaturas.

No RPG, cada participante faz o papel de um personagem que deve atuar em uma aventura imaginária (Jackson, 1994). Um dos participantes possui uma atuação diferenciada e é chamado "mestre". No desenrolar do jogo, o mestre atua como juiz, responsável pelo cumprimento de regras, e como narrador. O mestre elabora e apresenta um "cenário", correspondente à descrição de um ambiente ficcional que fornece o contexto para as ações dos personagens. Definido o cenário, o mestre passa a descrever cada situação que está imaginariamente acontecendo e diz aos jogadores o que os seus personagens estão percebendo, vendo, ouvindo. Em determinados momentos dessa narrativa, o mestre apresenta acontecimentos que criarão desafios para os personagens. Os jogadores, então, devem decidir e narrar como seus personagens irão atuar diante daquela situação desafiadora. Em seguida, ou mesmo interrompendo a ação dos personagens dos jogadores, o mestre apresenta sua narrativa de continuidade da situação e assim por diante.

O RPG é jogado de acordo com um conjunto de regras constitutivas, em forma de um manual, denominado "sistema". A ação de cada personagem baseia-se, tipologicamente, em uma ficha, construída pelos jogadores, levando-se em consideração elementos da inter-relação sistema/cenário. Ela é construída pelos jogadores, envolvendo negociações diante das expectativas e motivações de cada um. Contém atributos 
qualitativos e quantitativos de um dado personagem, que dependem de lances de dados para se expressarem neste ou naquele momento do jogo, desta ou daquela maneira.

Durante a aventura e diante das sugestões esboçadas pelo mestre, os jogadores estabelecem objetivos mais ou menos claros para a ação de seus personagens e buscam agir em função deles.

\section{Método}

\section{Participantes}

Os jogadores eram seis, na faixa etária entre 20 e 30 anos, todos do sexo masculino e formados ou concluindo o curso de Biologia em uma universidade pública do Estado de São Paulo. Todos os participantes do grupo consentiram em dar as entrevistas e serem filmados durante o jogo, sendo conhecedores dos objetivos da pesquisa e tendo assinado o termo de consentimento de participação livre e esclarecida, conforme as normas do CONEP. O pesquisador era amigo dos jogadores e participava do grupo antes do início da pesquisa.

\section{Procedimento}

Foram filmadas cerca de 9 h e 30 min de interações, compreendendo entrevistas do pesquisador com o mestre, com os jogadores e sessões de jogo de um grupo de RPG. As filmagens ocorreram em quatro dias diferentes em que o grupo espontaneamente se reuniu para jogar, sempre no mesmo local. $\mathrm{O}$ grupo não se reuniu para essa atividade nos intervalos entre as gravações. As entrevistas foram realizadas a cada dia, uma com o mestre do jogo e outra com o grupo de jogadores, cada uma delas com duração de cerca de 5 min.

Inicialmente, a introdução da câmera no campo situacional do jogo, bem como as entrevistas, parecem ter causado algum desconforto aos jogadores, que olhavam com certa constância ou agitação para a câmera. Posteriormente, contudo, ficaram à vontade, o que pôde ser constatado pelo linguajar e gestos descontraídos durante os diálogos, com desinteresse progressivo pela câmera.

Escolhemos um jogador que possuía uma maior disponibilidade de tempo (A) para nos fornecer uma perspectiva geral acerca da narrativa que vinha se constituindo antes do início das filmagens. Além disso, consultamos os livros do sistema e cenário que serviram de referência para o grupo, bem como o roteiro de campanha fornecido pelo mestre após a finalização da mesma.

\section{Análise de dados}

Procedemos à análise microgenética das filmagens segundo três etapas principais. Na primeira etapa, transcrevemos e sistematizamos as interações verbais do pesquisador com os jogadores e entre os jogadores. Esse trabalho de sistematização buscava mapear os recursos simbólicos balizadores das ações dos jogadores. Para tanto, contamos com o auxílio adicional da análise de livros e manuais do jogo e das perspectivas dos próprios jogadores reveladas nas entrevistas.

De acordo com Zittoun (2006), os recursos simbólicos oferecem definições temporalmente estáveis, permitindo a trilhagem de possíveis caminhos de ação para o objetivo desejado. Os elementos culturais são entendidos como mediações semióticas ou atos representacionais que se constituem como recurso a partir de seu uso intencional no contexto de transições significativas no campo da experiência cultural. Os usos dos recursos simbólicos podem ser verificados em relação à realidade social compartilhada, relações eu - outro ou nos processos de reflexão intrapessoal.

$\mathrm{Na}$ segunda etapa, procedemos à análise dos diálogos ocorridos nas entrevistas e nas sessões, organizando-os de acordo com tópicos, esferas e temas presentes como foco das expressões dos jogadores, isto é, de acordo com seus próprios referenciais semânticos (cf. Wertsch, 1991).

A terceira etapa consistiu da identificação de rupturas e transições (Zittoun, Duveen, Gillespe, Invision \& Psaltis, 2003) nos diálogos, tanto entre os personagens, como entre os jogadores. Demarcamos também os finais de turno de diálogo sobre um tema ou sub-tema da conversa.

Essas três etapas de análise permitiram-nos identificar os momentos de rupturas e estabilizações simbólicas no diálogo e seus subseqüentes desdobramentos na continuidade do jogo.

\section{Resultados}

De maneira geral, a análise dos diálogos evidenciou momentos de tensão, inquietação e desassossego, característicos das relações de alteridade (Simão, 2003), que se alternavam com momentos em que o tecido dialógico apontava para a convergência, ou seja, compartilhamento e consenso sobre os temas da conversa.

Apresentamos, a seguir, a análise de cinco trechos seqüenciais de uma sessão, em que se evidenciam aspectos de compartilhamento e ruptura intersubjetivas na relação eu outro. Nas ilustrações, o mestre será identificado por M. Os jogadores e os nomes de seus respectivos personagens serão identificados por S (Oromé), F (Indigus), C (Marcius), A (Evildick) e D (Ilya Manyr). A campanha jogada pelo grupo se passa numa região do cenário de ficção conhecida como Mar da Lua (Forgotten Realms) (Greenwood \& Grubb, 1995). A cidade central na campanha é Phlan, parcialmente arruinada. A aventura se passava com os personagens na cidade de Phlan tentando retomar o controle da cidade e do templo de Tyr (um dos deuses do Cenário), nela localizado.

No momento selecionado a partir do jogo, fez-se necessário aos personagens dos jogadores encontrarem formas de apoio dos líderes locais (prefeita de Phlan e grupos diversos) para unirem forças contra um grupo inimigo, liderado por Fuzoul Chembryl, sumo sacerdote do deus maligno chamado Bane, líder de uma cidade vizinha, Forte Zenthil. Indigus (F) havia deixado o personagem Oromé $(\mathrm{S})$ em frente à prefeitura. Em seguida voou com seu 'pégasus' em direção à parte velha da cidade que precisaria de sua proteção. Após uma discussão sobre quais aliados dos personagens dos jogadores estariam dentro ou fora das muralhas da cidade, o mestre dirigiu-se a S (Oromé):

\footnotetext{
TRECHO 1:

M: Bom... a prefeita tá lá. [Mestre falando na voz de mestre do jogo].
} 
S: Prefeita, preciso saber qual a situação e queria ver com você a possibilidade de juntarmos os exércitos porque tem outras forças do lado de fora da... da... é..., da cidade que já está em combate com os orcs. Gostaria de saber uma outra coisa... [Jogador falando na voz de seu personagem].

M: Que forças são essas? [Mestre, em tom de surpresa, nesse momento também atuando na voz de um personagem].

Esse trecho ilustra, em primeiro lugar, um momento do jogo marcado por uma inversão do quadro usual de dominância, em que o mestre é o pólo dominante em sua relação com os jogadores. Nesse momento, o mestre se surpreendeu com recursos utilizados pelos jogadores em suas elaborações simbólicas para atingir seus objetivos no jogo.

Esse trecho evidencia, ainda, um momento de mudança imaginária dos selves, no sentido do "como se" que indicamos logo de início. $\mathrm{M}$ e o jogador $\mathrm{S}$ passaram a assumir o papel de seus personagens: o M, a voz da prefeita de Phlan; o S, a voz de Oromé. Essa troca de posição demandou dos jogadores um distanciamento de si mesmos para experimentarem a cena. Notamos ainda que esse deslocamento só foi possível graças à disposição de ambos ao estabelecimento de um modo comum de interação, ou seja, disposição para o compartilhamento intersubjetivo. Nessas falas dos jogadores, os tons de voz mudaram, inaugurando, no momento de interpretação dos personagens, outro ritmo de interação, pré-reflexivo e imediato.

\section{TRECHO 2:}

$S$.... o seu... forças do nosso lado que estão atacando esses orcs malignos que estão invadindo.

M: Mas então porque não atacaram ainda esses... esses orcs vieram sem... sem, agente não teve nenhum aviso da parte dos guardiões.

S: Já estão em combate, agora quero saber se o seu reforço vindo do Fuzoul Chembryl deve vir ou não? Vai chegar ou não?

M: Peraí, que reforço? [M., ainda na voz da prefeita, em tom mais sério].

$F$ : Menos S. [Comentário de F, cujo personagem não se encontra na cena].

Nesse trecho notamos ruptura no compartilhamento intersubjetivo, provocada pela interpretação do personagem Oromé, ao trazer um elemento simbólico imprevisto à cena (Fuzoul Chembryl). F, cujo personagem não se encontrava na cena, desestimulou $\mathrm{S}$, indicando que a assimetria no diálogo com a prefeita de Phlan não era aceitável. A prefeita, por sua vez, reagiu seriamente ao questionamento de Oromé, indicando dificuldade de compreender. Assim, o questionamento de Oromé provocou uma ruptura, ao menos em relação à expectativa da prefeita: ela parecia não supor que ele tivesse conhecimentos acerca da atual condição diplomática que sua cidade se encontrava, conforme a seqüência no Trecho 3 , abaixo descrito.

\section{TRECHO 3:}

S: Como? Você não tem uma parceria com ele?

$M:$ Não, não...

$S:$ Não?

M: Eu tenho uma, a parceria que eu já falei pra você, a parceria...
S: Mas não é uma cidade aliada à sua? [M abaixa a face, Me S se entreolham e sorriem, A bate palmas].

S: Gostou? [Comentário na voz de jogador, não-personagem]

M: Gostei. Põe uns duzentos pontos de experiência aí. [Comentário na voz de $M$, não-personagem]

A: O S é um filho da p., ele não falou que nada ia acontecer aqui! [Comentário do jogador, cujo personagem não se encontrava na cena].

Esse trecho evidencia $\mathrm{S}$ selecionando uma lacuna no discurso da prefeita e utilizando-a em favor do alcance de seus objetivos. Essa seletividade pode ter-se originado do desejo de $\mathrm{S}$ de que seu personagem pudesse dialogar com a prefeita de Phlan, manifestado já na entrevista anterior à sessão. Ao ser indagado sobre o que achava que iria acontecer, afirmou: "Eu... Eu acho que a gente deve conseguir falar... Tomar o templo, ainda espero que agente consiga tomar o templo. E quero resolver as pendências com a prefeita também, né. Eu acho que tem muita coisa pra fazer depois disso daí".

O jogador S não completou sua frase inicial na entrevista, provavelmente porque o mestre estava presente e o conhecimento de seus planos por este poderia estragar a surpresa no momento do jogo. Adicionalmente, o jogador afirmou querer resolver algumas "pendências" com a prefeita. Essas pendências estariam vinculadas ao objetivo de tomada do templo de Tyr, que também aparece em seu discurso.

A evidência de uma lacuna na justificativa da prefeita sobre o fato de não estar contando com a ajuda de seu suposto aliado numa situação de guerra veio a produzir uma ruptura no padrão de dominância do jogo. O mestre surpreendeu-se com a atuação do jogador, reagindo imediatamente com um sorriso. $\mathrm{O}$ mestre e $\mathrm{S}$ saíram da posição de seus personagens e o jogador perguntou ao mestre se ele gostou de sua atuação. $\mathrm{O}$ mestre respondeu afirmativamente e o recompensou com pontos de experiência, um recurso do sistema de jogo.

Essa situação de alternância de posições aponta claramente para um diálogo entre vozes dos diversos mundos que o self estrutura dialogicamente (Hermans \& cols., 1992). Os outros jogadores que acompanhavam a cena comemoraram a nova situação dialógica entre M (prefeita de Phlan) e S (Oromé), uma vez que isso aumentaria o poder deles sobre o cenário de jogo.

\section{TRECHO 4:}

M: Tá, o que que vocês... Tá, eu não vou contar com o Fuzoul Chembryl.

S: Não, eu tenho outras pessoas do lado de fora e mais os cavaleiros de Tyr aqui, que estão para... que estão aqui e já estão defendendo sua cidade de orcs.

M: Reúna os guardiões e vão dar apoio aos arqueiros nas... nas... nas torres, a nossa guarda... a nossa guarda local vai... vai reagir então...

$S: E$, precisamos defender a parte velha, ouvi chamados naquela direção.

M: É..., é, não já... já, eu já sei dos, já sei do ataque. Agente vai ter que se defender em todas as frontes, em todas as... as... a, em todas as frentes de... de... de combate ai!

S: Quero pedir permissão para você para comandar os... a, os nossos exércitos dentro da cidade. 
M: Não me desaponte!

[O grupo reage com euforia].

Aqui, mestre e jogadores retomaram as posições de seus personagens no diálogo. A prefeita percebeu-se mais frágil, ao não contar com Fuzoul Chembryl, enquanto Oromé explicita a ela que possui recursos para colaborar na salvaguarda da cidade - uma meta que era compartilhada por ambos.

Nesse trecho, Oromé reforça sua condição dominante, ao apontar que conhece os problemas mais urgentes da cidade. A situação culminou com um pedido de Oromé para controlar os exércitos de Phlan, pedido este que já não pôde ser negado, diante da canalização do olhar da prefeita para uma possibilidade única de solução dos conflitos, canalização esta feita pelas ações próprias do jogador.

É interessante notar aqui que um elemento da transição da ruptura, provocada por Oromé, a partir da seleção ativa de um problema no discurso da prefeita, constituiu um novo campo de ação para os personagens do grupo com o controle dos exércitos.

Novamente, reações eufóricas evidenciaram, no jogo, o que Crossley (1996) chama de condição radical da intersubjetividade, concomitante ao pensamento reflexivo e egológico dos jogadores que atuaram na cena.

\section{TRECHO 5:}

S: [Respondendo à prefeita] Não se preocupe com isso!

M: Então vá e... [na voz da prefeita] unleash hell above them [jogadores sorriem]. Desencadeie o inferno em cima deles. Vai (bate palmas)! Então tá, você está com o comando agora de todos os guardiões da... da cidade [voz de M, jogador].

F: Carta branca.

M: Carta branca pra bater. Você tem a unidade sua lá já preparada, depois agente dá os... as estatísticas... [voltando-se para F], a hora que você deixou...

S: Eu to indo pra muralha lá...

M: Tá, legal... anh... a hora que você chegou...

Nesse trecho percebemos, na primeira fala do mestre, seu deslocamento do diálogo como personagem (a prefeita de Phlan) para o diálogo tal qual um jogador. Essa alternância para uma posição que não parecia ainda ser a de mestre, configurou-se como a emergência de mais alguém, um alguém importante - dando apoio ao grupo. Em seguida, reconheceu o desejo do $\mathrm{F}$ ao autorizar a sua atuação como líder de exército. O mestre instaurou, assim, uma nova configuração do cenário. O principal foco de tensão da cena foi resolvido, com os jogadores alcançando o objetivo de conquistarem apoio para a guerra, condição para a continuidade da campanha, na realização de objetivos maiores.

Tornou-se, assim, possível continuar o jogo sob um novo referencial semântico, constituído na relação com o F e seu personagem Indigus. Observamos, portanto, uma forma de transição simbólica que deu conta da ruptura intersubjetiva anteriormente instaurada.

\section{Discussão}

Considerando-se que as relações no RPG - como as interações sociais em geral - se dão segundo ações comunicativas mutuamente dirigidas entre os envolvidos, cabe destacarmos, nas situações de jogo examinadas, como as ações comunicativas evidenciaram situações de ruptura, transição e continuidade (Zittoun, 2006; Zittoun \& cols., 2003) no jogo.

Para interpretar os resultados, tomaremos uma concepção importante da aborgadem sócio-cultural da mente que, ao discutir a centralidade do conceito de ação, salienta que a ação reciprocamente orientada - ação interativa - é a categoria analítica básica da qual emergem o ambiente e o funcionamento mental. Dada a relação fundamental entre ação e meios mediacionais, o indivíduo será considerado, de acordo com essa perspectiva (Wertsch, 1991), um "indivíduoagindo-com-meios-mediacionais" (p. 12).

De fato, na interação entre os jogadores na sessão de RPG ocorrem, predominantemente, descrições verbais do cenário e de ações de personagens. A observação da sessão de jogo indicou também que esses diálogos são permeados por discussões sobre regras, questionamentos acerca da composição do cenário e de um trabalho constante de reflexão, discussão e avaliação das ações dos personagens e atitudes dos jogadores. O processo comunicativo propiciado pelos jogos de RPG ganha complexidade graças à multiplicidade de vozes e temas que permeiam as interações.

Seguindo Marková (1997), adotamos a noção de interação como um processo cuja natureza particular é a de complementaridade e mútua interdependência das entidades interatuantes, em contraposição à idéia de interação entre entidades relativamente independentes entre si. Conforme essa noção, nem o eu, nem o outro e nem o mundo podem ser concebidos um a priori do outro; pelo contrário, eles vêm à existência juntos, tal qual uma relação figura-fundo: o que se torna 'figura' pode ser distinguido apenas em relação ao que se torna 'fundo'. A alteração da figura implica, portanto, modificação no fundo e vice-versa.

A importância dessa perspectiva a respeito dos processos interativos é que, conforme apontaram Valsiner e Branco (1997), a ênfase na distinção entre opostos torna possível compreender a relação entre os elementos interatuantes; uma vez definidas, por sua vez, essas relações podem ser usadas para explicar transformações particulares no desenvolvimento.

Nas sessões de RPG pudemos observar, com constante recorrência, a emergência de oposições de diversos tipos. Do trecho de sessão de jogo apresentado anteriormente, por exemplo, pudemos depreender algumas relações de oposição dialógica: mestre - jogadores, na negociação de um recurso simbolizado do cenário (os exércitos de Phlan); jogador-personagem, quando o mestre está interpretando a prefeita da cidade e o jogador interpretando seu personagem Oromé; sistema-cenário, quando o mestre distribui pontos de experiência ao jogador devido a sua boa interpretação do personagem, ou quando da citação de estatísticas, que posteriormente seriam necessárias para análise dos exércitos; realidade-fantasia, quando mestre e jogador alternam as vozes de seus personagens para uma análise em terceira pessoa da cena vivida, como no questionamento de $\mathrm{S}$ ao mestre sobre se este havia gostado de sua interpretação; jogador-jogador, quando F e A reprovam, com gestos e comentários, a iniciativa de $\mathrm{S}$ e ele insiste em sua estratégia interpretativa de negociação com o mestre. 
Essas observações nos remetem à polifonia do diálogo, discutida por Bakhtin (1992, ver também Wertsch, 1991), em que a expressão é a unidade de análise do processo comunicativo verbal, que se dá sempre a partir de um ponto de vista. Cada expressão é caracterizada primariamente por um referencial particular de conteúdo semântico, que deve ser levado em conta em associação com o aspecto expressivo do falante, que avalia emocionalmente aquele referencial. Nesse sentido, uma expressão sempre implica ao menos uma palavra ou sentença endereçada a alguém, ou seja, ela é descrita pela relação "quem disse o quê para quem e quando" (Simão 2003, p. 453), a partir da qual o significado pode emergir. Assim, as expressões acontecem imersas numa cadeia comunicativa da qual não são indiferentes; o referencial semântico depende, portanto, do lugar que uma expressão ocupa na relação com as outras (Wertsch, 1991).

Dado que uma fala pode produzir múltiplas interpretações, o significado não será inerente a um elemento simbólico isoladamente (Wertsch, 1991). Os modos como a linguagem é usada irão produzir significados a partir do contato com outras vozes; o significado construído se dará, então, no domínio intermental da co-autoria.

O termo "voz", trazido de Bakthin, envolve um fenômeno geral definido por Holquist e Emerson (citados por Wertsch, 1991) como personalidade falante ou consciência falante. Está envolvida aqui a concepção de que certos aspectos do funcionamento mental humano são vinculados ao processo comunicativo, ressaltando o fato de que as elaborações discursivas de cada indivíduo envolvem processos de natureza interativa, comunicativa, levados a cabo intrasubjetivamente. Conforme salienta Wertsch (1991), o conceito de voz nos lembra que, conforme Vygotsky (1934/1991, 1978/1994), a dimensão individual é derivada da social. Wertsch (1991) aponta também que, de acordo com Bakthin, os processos comunicativos são caracterizados pela dialogicidade de vozes heterogêneas, isto é, quando o sujeito produz uma expressão, ao menos duas vozes podem ser escutadas simultaneamente: a dele e a de para quem a fala dele é endereçada.

Desde essa ótica, pensamos que o diálogo nos RPGs pode constituir um campo de abertura para o sujeito experimentar aquilo que é diverso da sua perspectiva, seja no nível do conteúdo da fala, seja no da posição de si percebida na relação eu - outro. Dada sua heterogeneidade, o diálogo com o outro pode trazer ruptura de expectativas e inquietação para o sujeito (Simão, 2003). Essa experiência com a diversidade pode ser entendida como emergência de uma novidade no campo de sentido dos sujeitos, possibilitando a externalização de mudanças na relação com os outros.

De fato, pudemos observar a emergência de novidade em cada um dos recursos simbólicos sistematicamente estudados. O trecho que nos serviu acima de ilustração evidencia algumas dessas emergências. No âmbito do cenário, os jogadores conquistaram a possibilidade de uso de elementos, os exércitos internos de Phlan, que anteriormente eram de uso exclusivo do mestre. Com referência ao sistema, o combate em massa que decorreu do uso dos exércitos disponíveis naquele momento foi posteriormente praticado com uma regra de jogo inventada pelo grupo de jogadores. Quanto à dimensão dos personagens, o ganho acumulado de pontos de experiências permitiu a 'passagem de nível' do personagem de S, que a partir daí pôde escolher novos recursos - perícias, habilidades, ganho de pontos de vida etc. - para seu personagem. No âmbito da campanha, a possibilidade do uso daqueles exércitos viabilizou aos jogadores a realização de algumas de suas metas e posterior construção de novos objetivos.

Dessa maneira, também aqui, a possibilidade de múltiplas representações da realidade pelos sujeitos, ao abordarem um problema, foi uma implicação do diálogo, conforme apontou Wertsch (1991). Face à ruptura de expectativas na interação com o outro, o sujeito pode reconhecer a sua própria identidade enquanto vinculada a uma historicidade própria de si, e legitimar a identidade do outro como diferente da sua, ou seja, supor o outro como também um sujeito-agindo-por-meiosmediacionais, com representações próprias e estrangeiras da realidade, estabelecendo a possibilidade de entrar em relação com a diferença (Simão, 2003).

Tornar o outro comparável a si remete à porosidade, ou permeabilidade a ele, permitindo uma alternância no contexto de dominância prevalente. No diálogo com a prefeita, por exemplo, a disponibilidade dela em ouvir o personagem Oromé, e a permeabilidade conquistada por ele por meio da redução de dominância viabilizou a ruptura e a transição para uma situação nova no contexto da cidade sitiada de Phlan.

As relações de alteridade estão, portanto, entranhadas em experiências inquietantes que emergem da relação com o outro. A reorganização requerida por experiências inquietantes exige, conforme discutem Zittoun e cols. (2003), a transição de uma configuração simbólica anterior, que o sujeito já vinha construindo, para outra, que não exclui a anterior, mas a modifica, em uma relação de "encaixe". Essa transição é feita graças à mediação de recursos simbólicos.

Zittoun e cols. (2003) indicam que os elementos simbólicos são padrões estabilizados de interação e o que os torna um recurso é o fato de serem usados por alguém, com determinado objetivo, no contexto de uma transição. Isso resulta em uma re-contextualização significativa do próprio recurso, possibilitando que ele direcione o problema aberto por uma ruptura e o resolva. A noção de uso corresponde, nesse caso, ao emprego de objetos como instrumentos para se fazer algo: agir sobre ou a partir do mundo físico, do mundo social e da realidade psíquica. Os recursos simbólicos atuam para reorganizar o caos e a incerteza da situação presente, tal como se apresenta a cada ator, sugerindo possíveis ações e gerando novos problemas. No processo de transformação, são os dispositivos simbólicos que suportam a reorganização, sendo internalizados, modificando entendimentos de experiências e disponibilizando um reajuste a partir de novas experiências (Zittoun \& cols., 2003). Esses autores afirmam ainda que o processo de uso de recursos simbólicos é orientado para o futuro e pode ocorrer em diferentes níveis de reflexividade. É na interação interpessoal, e a partir do uso dos recursos simbólicos, que se constroem os objetivos das ações. Os recursos simbólicos oferecem definições temporalmente estáveis, permitindo a trilhagem de possíveis caminhos de ação para o objetivo, sendo, portanto um tipo especial de baliza de que o sujeito dispõe para produzir uma tensão a partir da diferença entre o que se percebe como 'sendo agora' e o alvo da ação, pautado no desejo.

No trecho que nos serviu de ilustração, S utilizou-se de conhecimentos sobre a situação de guerra em Phlan, ou seja, recursos simbólicos que organizaram sua ação diante 
da prefeita. Alguns outros recursos participaram do diálogo: a guerra eminente, a traição de Fuzoul Chembryl, os exércitos aliados a seu grupo de personagens e a suposição de fragilidade da prefeita. Fragilidade essa norteadora da ação de Oromé diante da prefeita de Phlan. Por sua vez, ao usar esses recursos simbólicos, o personagem deveria fazê-lo atrelando a si uma identidade que não representasse ameaça ao poder da prefeita, expressando possuir condições efetivas para ajudá-la na salvaguarda da cidade. Como destacado anteriormente, o jogador $\mathrm{S}$ foi de fato capaz de fazer isso em seu diálogo interpretativo.

\section{Considerações Finais}

A partir das descrições do RPG e da exposição dos diálogos ocorridos em sessões de jogo, ilustramos e discutimos aspectos do processo de negociação intersubjetiva de significados numa situação em que os participantes buscavam compartilhamento em sua relação com o outro. Ao buscarem o compartilhamento, contudo, os jogadores de RPG entraram em contato com aspectos do outro que excediam suas expectativas.

Associamos ao contato com aspectos da alteridade do outro a ação simbólica dos jogadores, propiciadora de inquietações e desassossegos em diversos momentos. O estranhamento com o outro, emergente em alguns momentos da relação intersubjetiva, rompeu o contexto de compartilhamento. Os jogadores, por sua vez, realizaram processos de transição para situações mais estáveis, reorganizando os elementos do cenário de jogo, suas regras, os personagens e suas compreensões acerca da historicidade da narrativa por eles co-construída. No processo de transição, o acordo conseguido se expressou por uma novidade criativa emergida no campo das relações sociais.

As manifestações de prazer, mais evidentes durante a sessão de jogo, ocorreram quando a conquista de seus objetivos se deu a partir da emergência de uma solução surpreendente, inovadora, fora do campo precedente de perspectivas dos sujeitos que participavam da interação. Um desses momentos pôde ser verificado na interação entre Oromé e a prefeita de Phlan.

Os aspectos aqui discutidos abrem-nos possibilidade para refletir sobre futuras questões de pesquisa no tocante às relações entre intersubjetividade e alteridade no diálogo. Uma dessas questões refere-se às possibilidades de focalizar criatividade e imaginação como esforços para o estabelecimento de compartilhamento intersubjetivo a partir da ruptura provocada pelo contato com a alteridade do outro. Outro aspecto interessante diz respeito ao poder e reconhecimento mútuo entre os jogadores como necessários à expressão e satisfação de seus objetivos e desejos.

Jogar RPG, portanto, pareceu-nos envolver - da parte dos jogadores - desenvolvimento de métodos de investigação de relações eu - outro e eu - eu, onde o desejo do outro é sempre suposto, questionado e confrontado com o desejo do eu. Nessas situações, como em diversos casos da experiência social humana, cada ator (jogador, personagem, terapeuta, paciente, pesquisador, participante da pesquisa etc.) cria sua história única e constrói sua narrativa dela, como recorte e reelaboração da história grupal, necessitando, para interagir, entender o desejo e a maneira com que o outro procede no seu recorte e na sua interpretação.

\section{Referências}

Bakhtin, M. M. (1992). Estética da criação verbal. São Paulo: Martins Fontes.

Crossley, N. (1996). Intersubjectivity: The fabric of social becoming. Londres: Sage.

Greenwood, E. \& Grubb, J. (1995). Uma viagem aos reinos. São Paulo: Abril Jovem.

Hermans, H. J. M. (1996). Opposites in a dialogical self: Constructs as characters. Journal of Constructivist Psychology, 9, 1-26.

Hermans, H. J. M. (2002). The dialogical self as a society of mind: Introduction. Theory \& Psychology, 12, 147-160.

Hermans, H. J. M, Kempen, H. J. G. \& van Loon, R. J. P (1992). The dialogical self: Beyond individualism and rationalism. American Psychologist, 47, 23-33.

Jackson, S. (1994). GURPS (Generic Universal RolePlaying System): Módulo básico (D. Q. Reis, Trad.). São Paulo: Devir. (Trabalho original publicado em 1992)

Malaby, T. M. (2007) Beyond play: A new approach to games. Games and Culture, 2(2), 95-113.

Marková, I. (1997). On two concepts of interaction. Em M. Grossen \& B. Py (Orgs.), Pratiques sociales et mediations symboliques (pp. 23-44). Bern \& Berlin: Peter Lang.

Rommetveit, R. (1979). On negative rationalism in scholarly studies of verbal communication and dynamic residuals in the construction of human intersubjectivity. Em R. Rommetveit \& R. Blakar (Orgs.) Studies of language, thought and verbal communication (pp. 147-161). London: Academic Press.

Simão, L. M. (2003). Beside rupture - disquiet; beyond the other - alterity. Culture \& Psychology, 9, 449-459.

Valsiner, J. (1989). Culture and the development of children's action - A theory of human development. New York: Wiley.

Valsiner, J. (1998). The guided mind: A sociogenetic approach to personality. Cambridge: Harvard University.

Valsiner, J. (2006). O espírito do afeto no corpo da racionalidade psicológica. Em M. T. A. Souza \& V. S. R. Bussab (Orgs.), Razão e emoção: diálogos em construção (pp. 13-23). São Paulo: Casa do Psicólogo.

Valsiner, J. \& Branco, A. (1997). Changing methodologies: A coconstructivist study of goal orientations in social interactions. Psychology \& Developing Societies, 9, 35-64.

Vygotsky, L. S. (1991). Pensamento e linguagem (J. L. Camargo, Trad.). São Paulo: Martins Fontes. (Trabalho original publicado em 1934)

Vygotsky, L. S. (1994). A formação social da mente (M. P. Villalobos, Trad.). São Paulo: Martins Fontes. (Trabalho original publicado em 1978)

Wertsch, J. V. (1991). Voices of the mind: A sociocultural approach to mediated action. Cambridge: First Harvard University.

Zittoun, T. (2006). Transitions: Development through symbolic resources. Greenwich, Connecticut: Information Age.

Zittoun, T., Duveen, G., Gillespe, A., Invision, G. \& Psaltis, C. (2003). The use of developmental resource in developmental transition. Culture \& Psychology, 9, 415-448.

Recebido em 28.06.2007

Primeira decisão editorial em 11.10.2007

Versão final em 05.11.2007

Aceito em 15.10.2008 